\title{
Effects of Internship Predictors on Successful Field Experience
}

\author{
FRED BEARD AND LINDA MORTON
}

Internships have become a necessity for mass communication students making the transition from college to career. Researchers note this necessity: Kosicki and Becker (1995) report that 80 percent of journalism and mass communication undergraduates serve as interns. Rowland (1994) found that an internship is the "deciding factor" for most entry-level jobs, and Horowitz (1997) found that students' assessments of internship quality are significant predictors of future job satisfaction.

Mass communication programs recognize this necessity with most assisting students in locating internships (Basow \& Byrne, 1993) and many offering academic credit. The Accrediting Council on Education in Journalism and Mass Communications (ACEJMC) recognizes the legitimacy of internship credit, allowing credit for up to 10 percent of a student's course work (ACEJMC, 1997). However, there is little empirical evidence to assess the quality of internships, to provide schools with predictors of quality internships, or to determine the relative importance of various predictors in assuring successful internships.

This study deals with such evidence. Its purpose is to assess the relationship between two sets of linearly related variables: predictors of internship success and outcomes of successful internships. The characteristics of advertising and public relations interns and their internships are used as predictors. Interns' evaluations of the success of their internships are used as outcomes, or criterions. Focusing on the nature and strength of the relationships between predictors and outcomes, this study seeks to determine what needs to occur during an internship in order for beneficial outcomes to be realized.

\section{Predictors}

Six important predictors of internship success are suggested in the literature. These include: (a) academic preparedness, (b) proactivity/aggressiveness, (c) positive attitude, (d) quality of worksite supervision, (e) organi-

Beard (FBEARD@OU.EDU) is associate professor of journalism and Morton is associate professor of journalism at the University of Oklahoma. 
zational practices and policies, and ( $f$ ) compensation.

Academic preparedness. Several researchers note that successful interns are well prepared academically (Basow \& Byrne, 1993; Beard, 1997; Campbell \& Kovar, 1994). For many programs, academic preparation includes a specific number of completed credits, including a number of mass communication courses with an acceptable grade point average. Bourland-Davis, Graham and Fulmer (1997) note that interns should at least have "an understanding of the field, its key concepts, and basic technological skills, especially writing" (p. 27).

The importance of academic preparedness is emphasized by Basow and Byrne (1993), who warn that some students should be cautioned "against attempting some internships prematurely" (p. 52). Similarly, Beard (1997) notes that one of the most significant findings from his study of interns is "that academic preparation leads to more and better opportunities on most internships" (p. 8).

Proactivity/aggressiveness. The literature indicates that students are more likely to have successful internships if they demonstrate initiative (Basow \& Byrne, 1993; Beard, 1997) and are aggressive in making their wants and needs known. Basow and Byrne, for instance, recommend that students be encouraged to be aggressive by volunteering for assignments and asking questions. Similarly, Beard (1997) notes that there is an "almost universal assumption" among interns and their supervisors that interns should demonstrate initiative by finding things to do and asking questions (p. 10). Beard also found that when interns make their wants and needs known, their supervisors generally respond positively.
Positive attitude. The literature suggests that students will more likely have a successful internship if they have a positive attitude toward it as both a learning and occupational experience. In his study of interns and their supervisors, Beard (1997) found that both groups emphasized the importance of interns treating almost any task as a potential learning experience. Students are also expected to realize greater benefits from an internship if they treat it like a real job. Beard found that many internship supervisors expect interns to come to the worksite ready to work and to exhibit the same attitudes as new, full-time employees. Similarly Bourland-Davis et al. (1997) suggest that interns should have accurate expectations and set appropriate goals for the internship.

Quality of supervision. Beard (1997) found that good supervisors manage the relationship with their interns by providing specific direction and examples, some autonomy and independence, and positive and constructive work-related feedback. Similarly, Taylor (1992) notes that good supervisors are supportive, increasing, rather than lowering, the intern's self-esteem. Such supervisors "demonstrate high work standards and competence, provide frequent feedback, develop the individual through coaching" (Taylor, $p$. 56), evaluate interns, and help interns to "understand how the isolated activities and encounters fit within the scope of an entire . . . program" (BourlandDavis et al., 1997, p. 31).

Gabris and Mitchell (1992), in their survey of public administration interns, found that effective supervision was strongly and significantly correlated with an overall "intern satisfaction index." They conclude that " . . . supervisors who .... work to develop 
interesting and challenging assignments for their interns are more likely to find their interns satisfied with the educational benefits of the experience" ( $p$. 191).

Organizational practices and policies. Related to the effectiveness of an intern's supervisor are the practices and policies that organizations use to structure and manage internships. Structure includes considering the length and appropriate terms of internships, establishing basic expectations, and conducting weekly intern meetings (Bourland-Davis et al., 1997).

Managing internships includes: (a) providing interns with the physical and other resources needed to accomplish assigned work (Beard, 1997), (b) providing interns with an experience that approximates that of a full-time employee (Verner, 1993), (c) providing students with the opportunity to work on projects from inception to completion (Beard) with little "busy work" (Campbell \& Kovar, 1994; Krasilovsky \& Lendt, 1996), and (d) providing appropriate study programs for the site (Bourland-Davis et al., 1997).

Compensation. Research indicates that interns have more successful internships if they are compensated for their work. Basow and Byrne (1993) contend that compensation should at least include academic credit. ACEJMC agrees. It developed Standard 7 to guide schools in offering internships for credit (ACEJMC, 1997).

However, other researchers contend that payment is the best compensation for an intern's work. Basow and
Byrne (1993) found that interns receiving payment evaluated their internships higher. Moreover, Beard (1997) found that "even token payment appears to lead to many positive consequences, such as reduced physical and mental stress for students and a more positive outlook toward the value of the internship" (p. 18).

Other writers suggest that monetary compensation leads to more successful internships for four reasons. First, it reminds students that they are entering the "real world" and should treat the internship like a job (Beard, 1997: Hamilton, 1992). Second, it implies a commitment on the part of the sponsoring organization to make the internship meaningful (Hamilton). Third, it helps students offset the loss of income from other part-time jobs (Beard; Berger, 1992). Fourth, it helps students justify an internship to parents, who are often bearing much of the financial costs for college and who may discourage students from doing unpaid internships (Berger).

\section{Outcomes}

An extensive body of research, conducted in a variety of professional disciplines, suggests that the success of an internship might be appropriately evaluated using five constructs. These 
include: (a) acquisition of technical skills, (b) career-related benefits, (c) career focus, (d) acquisition of interpersonal skills, and (e) outcomes of a more practical nature.

Acquisition of technical skills. The acquisition of technical, work-related skills is almost synonymous with the notions of "experiential learning" and "internship." College graduates are increasingly competing with the underemployed and victims of corporate layoffs, who already possess substantial work skills. It is not surprising, then, that Beard (1997) found that all his study respondents "recognized the importance of the intern gaining 'real world' experience from the internship, including technical job skills" (p. 6).

Career benefits. For students, career benefits include: (a) improving prospects for obtaining entry-level jobs (Horowitz, 1996; Perlmutter \& Fletcher, 1996), (b) obtaining mentors (Basow \& Byrne, 1993; Verner, 1993), (c) acquiring a new recognition of the relevance of college course work, (d) attending regular professional development seminars and participating in mock interviews (Brightman, 1989; Farinelli \& Mann, 1994), (e) developing a professional attitude, and (f) developing prioritization and organization skills (Bourland-Davis et al., 1997, p. 31).

Career focus. Another benefit presumed to accrue to students includes greater focus on a career path (Perlmutter \& Fletcher, 1996). Career focus includes a recognition of the vocational abilities students should be able to offer future employers, as well as those they will need to be successful in their careers (Taylor, 1992). Thus, career focus is believed to lead to more positive beliefs about the intern's career choice and is also believed to be correlated with future job satisfaction (Tay- lor).

Acquisition of interpersonal skills. Some researchers have noted the importance of internships in developing students' interpersonal skills (Beard, 1997) and adjusting to the culture and climate of the professional workplace (Campbell \& Kovar, 1994). In fact, after their internships, many students "report a newfound appreciation for the interpersonal and communication skills required of the professional in the workplace" (Beard, p. 6).

Practical outcomes. Beard (1997) found that, while gaining "real world" job experience is an important outcome of an internship, tangible evidence of this experience is equally important. Thus, practical outcomes include materials for portfolios and job interviews, personal references, and simply being able to demonstrate the use of common workplace technologies, such as fax machines and copiers.

\section{Research questions}

The overall purpose of this study is to explore and assess the nature and strength of the relationship between the characteristics of interns and internships (as predictors) and intern evaluations of the positive outcomes by which they assessed the success of their internships (as criterions). Thus, the following research questions were addressed in this study:

Question 1: What proportion of advertising and PR students experience an internship that has beneficial outcomes?

Question 2: To what extent does a relationship exist between the predictors of a successful internship and positive outcomes?

Question 3: What is the proportion of variance in internship outcomes that is predictable from knowledge of intern- 
ship and intern characteristics?

Question 4: Which of the characteristics of internships and interns are most highly predictive of successful internship outcomes?

\section{Method}

Data were gathered from a national sample of advertising and PR students. It was not possible to construct a sampling frame of all advertising and PR interns, both for-credit and not-forcredit, and to sample randomly from it. However, given the goals of this study, which are more analytical in nature, a purposive sample consisting of students who had recently completed internships was deemed appropriate. Thus, respondents were identified by first identifying and contacting academic internship supervisors and coordinators at the 102 accredited journalism and mass communication programs listed in the ACEJMC annual publication (1997).

Twenty-four of the contacted programs agreed to administer the survey to students who would complete an internship during a summer semester, gather the completed questionnaires, and return them to the study's investigators. The participating 24 programs produced a total of 193 respondents.

Sample. In terms of degree area, the largest proportion of respondents ( $n$ = 193) declared themselves $P R$ majors $(60.6 \%)$, followed by advertising (25.4\%), and "other" (14.4\%). Becker and Kosicki's recent survey (1997) of journalism and mass communication enrollments reveals that, of the total students enrolled in advertising and PR, 46.1 percent are in $P R, 39.7$ percent are in advertising, and 14.2 percent are in combined programs. Thus, advertising students are somewhat under-represented in the present sample.

Almost all the respondents re- ceived academic credit for their internships (95.3\%), with 58 percent receiving some form of monetary compensation. The most common internship site was a PR/advertising agency (25.8\%), followed by "other" $(22.8 \%)$, and business/industry (18\%). Females represented a greater proportion of respondents (82.4\%) than the recent survey of journalism and mass communication undergraduates (Becker \& Kosicki, 1997 $=59.4 \%$ female respondents) or a recent survey of a large midwestern university's JMC graduates (Horowitz, $1997=73 \%$ female respondents). Thus, females are somewhat overrepresented in the sample.

Similarly, a larger proportion of respondents $(\mathbf{8 9 . 5 \% )}$ classified themselves as "white" than in Becker and Kosicki's 1997 survey (79.3\% white graduates). Finally, respondents reported a mean GPA of 3.28.

Measures. The survey instrument was a self-administered questionnaire, consisting of three major sections: (a) assessment of predictors, (b) assessment of criterions, and (c) demographic and other descriptive data. A five-point, Likert-type response, ranging from "strongly disagree" (1) to "strongly agree" (5), was used to construct multiitem, composite scales. The instrument was pretested among a sample of advertising and PR interns prior to its use in the survey. Some items were revised to improve clarity and scale reliability.

Predictors. Six items were used to measure the extent to which interns believed they were academically prepared for their internships (e.g., "My college courses gave me the skills I needed to perform well on my internship"). The extent that interns reported being proactive and aggressive during their internships (e.g., "I often volunteered for tasks during my internship") 
was assessed using four items.

Four items assessed the positive attitudes interns held toward the internship as both a learning and work experience opportunity (e.g., "I treated my internship like a real job"). The quality of the intern's supervision and effectiveness of his or her supervisor were assessed with eight items (e.g., "My supervisor considered my interests and goals and adapted the internship accordingly").

Organizational practices and policies were assessed using six items (e.g., "My work was very similar to that of a full-time, entry-level employee"). Finally, whether a respondent received some form of monetary compensation was included in the analysis as a dummy variable.

Outcomes. The extent to which students reported that the experience led to the acquisition of technical job skills was assessed with five items (e.g., "I got lots of 'hands-on' experience"). Four items measured the extent to which the internship provided careerrelated benefits (e.g., "I developed a mentor relationship with someone during my internship").

Four items were used to assess the career-focus benefits of the internship (e.g., "I now have a better focus on where my career is going"). The acquisition of interpersonal skills was assessed with three items (e.g., "I-improved my interpersonal skills when it comes to working with others"). Other practical outcomes resulting from the internship were assessed with five items (e.g., "I completed projects I can use in my portfolio").

The predictor and outcome items were subjected to two separate principal components factor analyses (varimax and oblimin rotations), prior to their use in scale construction. Some items were deleted from the analysis when they failed to discriminate among the factors in the solutions. The scales were then constructed by categorizing the remaining items, summing the item scores, and dividing by the number of items in each scale. Basic scale characteristics and reliabilities are reported in Table 1. Reliability coefficients for all the scales in the study indicate acceptable reliability, with Cronbach alphas ranging from .60 to .91 (Nunnally, 1978).

Demographic and other descriptive items. The final section of the questionnaire included declared major, type of internship worksite, sex, GPA, race, and whether interns received academic credit.

\section{Analysis}

Descriptive statistics were used to assess the demographics of the sample and to answer Research Question 1: What proportion of advertising and PR students experience an internship that has beneficial outcomes? Canonical correlation analysis was used to answer Research Questions 2 - 4: (2) to assess the strength of the relationship between the set of predictor variables and the set of criterion variables, (3) to determine what proportion of variance in successful internships is accounted for by the predictors, and (4) to identify the predictors that are most highly predictive of a successful internship.

Canonical correlation analysis, as opposed to simple bivariate correlation or multiple regression, was used in this study because the principal concern is with the structural relationships between the two sets of data holistically, and not in the associations between individual variables or the prediction of a single criterion variable (Clark, 1975; Levine, 1977). 


\section{Results}

The results indicate that most interns in the sample completed their internships with high evaluations of their success. In addition, the results of the canonical analysis reveal that (a) the sets of predictor and criterion variables are highly correlated, (b) that the predictor variables account for almost onehalf the variance in the criterion set, and (c) that quality of supervision is the most important predictor variable.

Research Question 1: What proportion of advertising and PR students experience an internship that has beneficial outcomes? The majority of interns agreed that their internships were successful, based on agreement scores of 4.00 and above on a scale of agreement of 1.00 to 5.00 . The largest proportion $(75.2 \%)$ agreed that their internships helped them to acquire interpersonal skills. The smallest proportion $(59.8 \%)$ agreed that the internship successfully gave them greater career focus. Interns agreeing that their internships were successful in producing other outcomes fell within this 15-point range: acquisition of technical skills $=70.1$ percent, career benefits $=69$ percent, and practical outcomes $=65.3$ percent.

When the results above are combined with the mean scores on the outcomes scales (Table 1), it is evident that interns evaluated their internships very highly. Mean agreement scores on the outcomes scales are above 4.00 on every outcome.

Research Question 2: To what extent does a relationship exist between the predictors of a successful internship and positive outcomes? The canonical analysis produced two statistically significant roots. However, Root 2 had a $\mathrm{Rc}$ of less than .30, the rule-of-thumb for meaningful interpretation (Tucker \& Chase, 1980). In addition, the variance of the successful internship outcome variables explained by the predictors in Root 2 was trivial (.006). Thus, further interpretation of the results are confined to the findings contained in the first root.

The first root resulting from the canonical analysis is shown in Table 2. Root 1 indicates that the sets of predictor and criterion variables are highly

\title{
TABLE 1
}

\section{Basic Scale and Variable Characteristics: Means, Standard Deviations, and Scale Reliability Estimates}

\author{
Scale \\ 1. Academic Preparedness \\ 2. Proactivity/Aggressiveness \\ 3. Positive Attitude \\ 4. Quality of Supervision \\ 5. Organizational Practices/Policies \\ 6. Acquisition of Technical Skills \\ 7. Career Benefits \\ 8. Career Focus \\ 9. Acquisition of Interpersonal Skills \\ 10. Practical Outcomes
}

\section{$M$}

3.90

4.18

4.37

3.80

3.77

4.20

4.17

4.07

4.24

4.06

$\begin{array}{ccc}S D & n & \text { alpha } \\ .75 & 191 & .78 \\ .63 & 193 & .64 \\ .56 & 192 & .60 \\ .96 & 188 & .91 \\ .83 & 191 & .81 \\ .74 & 193 & .87 \\ .70 & 193 & .76 \\ .71 & 192 & .82 \\ .68 & 193 & .79 \\ .74 & 189 & .67\end{array}$

Note: Number of respondents ( $n$ ) varies due to missing responses. 
and significantly correlated $(\mathrm{Rc}=.84$, $\chi^{2}=233.056, \mathrm{p}<.0001$ ). The interpretation of canonical variates typically involves focusing on the variable loadings with the highest absolute values (Tucker \& Chase, 1980). Thus, it is clear that the Set 1 variate is somewhat dominated by the quality of supervision variable, although the organizational practices and policies and positive attitude variables substantially define the variate and are also highly correlated with it. Likewise, academic preparedness is substantially correlated with the variate.

Interestingly, interns' proactivity/ aggressiveness and whether or not they received compensation for their internships are not correlated as highly with the predictor variate. However, the magnitudes of their loadings do indicate they are moderately correlated with the predictor variate and do contribute to its construction.
Set 2 loadings are dominated by practical outcomes and the acquisition of technical skills, although the very high loadings for all the variables define a variate that uniformly captures the concept of a "successful internship."

The loadings of the variables in both sets, as well as the consistent directions of the coefficient signs, make interpretation of the variates and their relationships straightforward. Interns who rate high the quality of internship supervision, organizational practices, and policies, and positive attitude, and who rate themselves moderately high on academic preparedness - tend also to rate the quality of their internships higher on every dimension.

Research Question 3: What is the proportion of variance in internship outcomes that is predictable from knowledge of internship and intern characteristics? The redundancy of Set

\section{TABLE 2 \\ Canonical Structure (Root 1): INTERNShIP Predictors and CRITERIONS}

Scales

Predictor Scales

1. Academic Preparedness

2. Proactivity/Aggressiveness

3. Positive Attitude

4. Quality of Supervision

5. Organizational Practices

6. Compensation
Loadings

$-.502$

$-.387$

$-.753$

$-.895$

$-.784$

$-.301$
Canonical Variate Standardized Coefficients

Criterion Scales

1. Acquisition of Technical Skills $\quad-.905$

$-.175$

$-.086$

$-.299$

$-.571$

$-.131$

$-.133$

2. Career Benefits

$-.879$

$-.370$

$-.756$

$-.318$

3. Career Focus

.016

4. Acquisition of Interpersonal Skills

$-.662$

$-.031$

5. Practical Outcomes

$-.911$

$-.415$

$R c=.84, R c^{2}=.70, \chi^{2}=233.056, d f=30, p<.0001$. Redundancy:

Set 2 given Set $1=48$ percent. 
2 (outcomes) given Set 1 (predictors) is .48. In sum, approximately one-half of the success of an internship, as measured in this study, is predictable from a knowledge of the variables in the predictor set.

Research Question 4: Which of the characteristics of internships and interns are most highly predictive of successful internship outcomes? It is clear that quality of supervision is the most important single predictor variable of the general "good internship" variate described by the variables in the criterion set. However, it is also clear that all the predictor variables are predictive of an intern's overall evaluation of successful outcomes resulting from his or her internship. The importance of the predictors, after quality of supervision (based on the magnitudes of their loadings), are organizational practices/policies, positive attitude, academic preparedness, proactivity/aggressiveness, and compensation, in that order.

\section{Discussion}

Given the importance of an internship to the future career of an advertising or PR student, it is encouraging to discover that such a large proportion of students had what they believe to be a successful internship. This is consistent with other research on journalism and mass communication interns, such as Horowitz's study (1997), which found that the mean satisfaction score, on a 1-to-10 scale, with 10 rated as "excellent," was 8.45. Conversely, the frequency of unsuccessful internships that led Perlmutter and Fletcher (1996) to ask: "Why do so many fail? Why do horror stories abound?" (p. 5), may not, fortunately, be all that frequent.

The high ratings of internship success reported by the respondents to this survey suggest that granting academic credit for internships is appropriate. Furthermore, since the sample consists of students enrolled in ACEJMC-accredited programs, which are presumably following ACEJMC internship guidelines, the results suggest that these guidelines may be contributing substantially to successful internships.

It is important to note, however, that a far smaller proportion of students agreed that their internships led to an increase in career focus. At first, this result might suggest a need for improvement. However, it is also important to remember that many students use internships to test different career possibilities, and may, in fact, reject some career paths based on the outcomes of these internships. Thus, such internships may not necessarily seem to lead to improvements in career focus, yet they are beneficial in testing different career possibilities.

The results of this study represent substantial progress in the effort to understand specifically what needs to happen during an internship in order for it to lead to successful outcomes. Although the literature had suggested the predictors of a successful internship, this study confirms their importance. Furthermore, the results empirically confirm how much of a successful internship can be predicted from a knowledge of these predictors.

De Mott (1972), Basow and Byrne (1993) note that "Most media managers and executives try to make such internships meaningful learning experiences for the students involved ..." (p. 48). The moderately high evaluations of both supervisor effectiveness and organizational practices and policies found in this study support this conclusion. However, because the quality of super- 
vision and organizational practices and policies regarding internships proved to be the best predictors of a successful internship, this study indicates that journalism and mass communication programs should concentrate more on training internship supervisors and

programs consider students' attitudes when deciding if they are ready for an internship, and even fewer require that students intern with only approved worksites and supervisors. In this respect, it is important to note that the respondents to this survey rated qual-

ity of supervision and organizational practices and policies good. However, these ratings were lower than those of the other variables respondents used to describe themselves and their internships.

The results

suggest that implementing re-

helping students select quality worksites.

It is also important to note the very high correlation between the positive attitude variable and successful internships. This result strongly suggests that students should be encouraged to treat their internships like real jobs. They need to dress appropriately, be on time, and be at the worksite when they are scheduled to be there.

In sum, many of the results of this study indicate that successful internships depend most on predictors to which journalism and mass communication programs appear to give the least time and attention. Most programs require that interns have a certain number of completed credits with an acceptable grade point average. Yet, such academic preparedness proved considerably less important than other predictors for which most programs are not presently controlling. For instance, few quirements regarding the selection of worksites and supervisors, and encouraging students to treat their internships like real jobs, will improve internships more than requirements regarding the other predictor variables. As examples, supervisors should be encouraged to provide specific direction, examples, and positive, constructive feedback. In deciding whether to approve a worksite, journalism and mass communication programs should consider whether the organization is implementing appropriate practices and policies regarding interns. At the least, organizations should manage their internships so they provide students with an experience that approximates that of a full-time employee.

However, it is important to note that proactivity/aggressiveness and compensation are moderately correlated with successful internship outcomes. These results suggest students 
should continue to be encouraged to volunteer for assignments, ask questions, and to be aggressive about making their wants and needs known.

Finally, journalism and mass communication programs should encourage organizations wanting interns to pay them. Beard (1997) contends that the payment doesn't have to be much. Just paying students' tuition for the internship credit can have a positive influence on interns' perceptions of their internships. However, the fact that monetary compensation is only moderately associated with successful internships is probably a result of interns' willingness to accept unpaid internships as "part of paying their dues."

\section{Study limitations}

One limitation of the present study is the generalizability of its results. The study should be replicated with a random sample including other journalism and mass communication fields as well as programs that are not accredited by ACEJMC.

A second limitation is the study's response rate at the program level. Telephone conversations with some nonresponding programs suggested that many could not participate because they had no one responsible for monitoring internships in what a few called a "formal" sense.

A third limitation is the study's reliance on a self-administered survey questionnaire, which can be susceptible to various sources of error.

Fourth, there is clearly room for improvement in the psychometric properties of some of the predictor and outcomes scales developed for this study.

Finally, it is important to note that canonical correlation, as a mathematical maximization technique, can pro- duce inflated results. Similarly, Tucker and Chase (1980) note that "canonical structures may be highly unstable from sample to sample. .." (p. 223). Thus, the validity and reliability of the present results should be assessed with a replication, repeating the study on a comparable sample.

Accrediting Council on Education in Journalism and Mass Communications. (1997). Journalism and mass communications accreditation. Lawrence, KA: Author.

Basow, R. R., \& Byrne, M. V. (1993). Internship expectations and learning goals. Journalism \& Mass Communication Educator, 47(4), 48-56.

Beard, F. K. (1997, August). Inside the advertising and public relations internship. Paper presented at the annual conference of the Association for Education in Journalism and Mass Communication, Chicago, IL.

Berger, J. (1992). Making an internship work. In A. Ciofalo (Ed.), Internships: Perspectives on experiential learning (pp. 211-218). Malabar, FL: Krieger Publishing Company.

Bourland-Davis, P. G., Graham, B. L., \& Fulmer, H. W. (1997). Defining a public relations internship through feedback from the field. Journalism \& Mass Communication Educator, 52(1), 26-33.

Brightman, D. E. (1989, January). Build an internship program. Public Relations Journal, 29-30.

Campbell, K., \& Kovar, S. K. (1994). Fitness/ exercise science internships: How to ensure success. The Journal of Physical Education, Recreation \& Dance, 65(2), 69-73.

Clark, D. (1975). Understanding canonical correlation analysis. London: The Institute of British Geographers.

Gabris, G. T., \& Mitchell, K. (1992). Exploring the relationships between intern job performance, quality of education experience, and career placement. In A. Ciofalo (Ed.), Internships: Perspectives on experiential learning (pp. 179-194). Malabar, FL: Krieger Publishing Company.

Hamilton, R. A. (1992). Internships are key to direct marketing program. In A. Ciofalo (Ed.), Internships: Perspectives on experiential learning (pp. 219-221). Malabar, FL: Krieger Publishing Company.

Horowitz, E. M. (1997, August). Does money still buy happiness: Effects of journalism internships on job satisfaction. Paper presented at the annual conference of the 
Association for Education in Journalism and Mass Communication, Chicago, IL.

Horowitz, E. M. (1996, August). Chasing the pot of gold: Internships on the road to employment. Paper presented at the annual conference of the Association for Education in Journalism and Mass Communication, Anaheim, CA.

Kosicki, G. M., \& Becker, L. B. (1997). Annual survey of enrollment and degrees awarded. Journalism \& Mass Communication Educator, 52(3), 63-74.

Kosicki, G. M., \& Becker, L. B. (1995, August). Annual survey of journalism and mass communication graduates. Paper presented at the annual meeting of the Association for Education in Journalism and Mass Communication. Washington, D. C.

Levine, M. S. (1977). Canonical analysis and factor comparison. Sage University Paper series on Quantitative Applications in the Social Sciences, 07-001. Beverly Hills: Sage Publications.

Nunnally, J. C. (1978), Psychometric theory (2nd ed.). New York: McGraw-Hill.
Perlmutter, D. D., \& Fletcher, A. D. (1996, August). Feedback that fits: How experienced and naive mass communication students view internships. Paper presented at the annual conference of the Association for Education in Journalism and Mass Communication, Anaheim, CA.

Rowland, M. (1994, June 5). Getting before-thejob-experience; an internship often provides the path to ease into a career. The New York Times, p. F15.

Taylor, M. S. (1992). Effects of college internships on individual participants. In A. Ciofalo (Ed.), Internships: Perspectives on experiential learning (pp. 52-76). Malabar, FL: Krieger Publishing Company.

Tucker, R. K., \& Chase, L. J. (1980). Canonical correlation. In J. Capella \& P. R. Monge (Eds.), Multivariate techniques in human communication research (pp. 205-228). New York: Academic Press, Inc.

Verner, E. M. (1993). Developing professionalism through experiential learning. The Journal of Physical Education, Recreation \& Dance, 64(7), 41-45. 